\title{
The Effect of Temperature on the Hydrogen Permeation of Pipeline Steel in Wet Hydrogen Sulfide Environments
}

\author{
Zhu Wang ${ }^{1}$, Mingliang Liu ${ }^{1,2}$, Minxu Lu $^{1,}{ }^{*}$, Lei Zhang ${ }^{1}$, Junyan Sun ${ }^{1}$, Ziru Zhang ${ }^{1}$, Xian Tang ${ }^{1}$ \\ ${ }^{1}$ Institute for Advanced Materials and Technology, University of Science and Technology Beijing, \\ Beijing 100083, PR China \\ ${ }^{2}$ Baoshan Iron \& Steel Co., Ltd., 201900, PR China \\ E-mail: Lumx@ustb.edu.cn
}

doi: $10.20964 / 2018.01 .52$

Received: 23 September 2017 / Accepted: 12 November 2017 / Published: 16 December 2017

\begin{abstract}
In this study, the effect of temperature on the hydrogen permeation of pipeline steel in wet $\mathrm{H}_{2} \mathrm{~S}$ environments was studied. The steady-state permeation current density, steady-state flux, and the permeation rate increased with increasing temperature. The corrosion rate increased at $35^{\circ} \mathrm{C}$ and was confirmed by the electrochemical tests. The result of this study indicated that the corrosion process was controlled by the cathodic reaction. The hydrogen permeation behavior in under wet $\mathrm{H}_{2} \mathrm{~S}$ condition was affected by the corrosion rate and the corrosion product.
\end{abstract}

Keywords: pipeline steel, hydrogen sulfide, temperature, hydrogen permeation

\section{FULL TEXT}

(C) 2018 The Authors. Published by ESG (www.electrochemsci.org). This article is an open access article distributed under the terms and conditions of the Creative Commons Attribution license (http://creativecommons.org/licenses/by/4.0/). 